\title{
Wallasea Island Wild Coast Project
}

\author{
Adrian Wright ABP Marine Environmental Research, awright@abpmer.co.uk \\ Colin Scott, ABP Marine Environmental Research, cscott@abpmer.co.uk
}

Wallasea Island lies between the Crouch and Roach Estuaries on the East Coast of the UK. This coastline which includes the large agricultural area of Wallasea Island has been identified as an area which is at immediate risk of unmanaged breaching. Without some kind of managed intervention, flooding of Wallasea Island is likely to lead to significant adverse impacts on the surrounding estuaries and existing coastal defence structures.

It is proposed through the use of Managed Realignment to return Wallasea Island from an agricultural area into a wild coast that resembles it natural form. Without proper management this whole area is subject to complete inundation and if left unmanaged would result in the significant adverse impacts to the whole Crouch and Roach Estuary System, as the tide gradually fills his large tidal basin. To achieve a sustainable managed environment the Royal Society for the Protection of Birds (RSPB) intend to use beneficial dredge material to increase the land elevations within Wallasea Island.

This paper describes the key design stages of this unique project and provides an example of how managed realignment offers an opportunity to reduce environment risks whilst gaining significant areas of lost intertidal habitat. 